\title{
REEMPLAZO DE TRABAJADORES HUELGUISTAS EN LA REFORMA LABORAL
}

\section{REPLACEMENT OF STRIKING WORKERS IN THE LABOR REFORM}

\author{
JOAQUÍN RODRÍGUEZ SOZA* \\ Abogado
}

\begin{abstract}
RESUMEN: En la reciente Reforma Laboral de Chile se intentó eliminar definitivamente la posibilidad del empleador de reemplazar a los trabajadores que se encontraran en huelga durante la negociación colectiva. Sin embargo, durante su tramitación, se introdujo una indicación presidencial que matizó el alcance de esa prohibición, por lo que resulta imprescindible determinar la discusión que formó la Historia de la Ley. De esta forma, comienza desde ya la interpretación de esta norma, que guiará a la jurisprudencia que inevitablemente será protagonista en su aplicación y en el cumplimiento de los estándares nacionales e internacionales de Libertad Sindical.
\end{abstract}

PALABRAS CLAVES: Huelga; Reforma Laboral; Negociación Colectiva; Libertad Sindical

ABSTRACT: Chile's recent Labor Reform, tried to definitely eliminate the employer's possibility of replacing striking workers during collective bargaining. However, during the drafting of the law, a presidential instruction was introduced to nuance the extent of that restriction; this makes it essential to determine the argument that shaped the History of the Law. Thus, begins the interpretation of this norm and will guide the jurisprudence that, doubtlessly, will play a main role in its application and compliance with national and international standards in Freedom of Association.

KEY WORDS: Strike; Labor Reform; Collective Bargaining; Freedom of Association

\section{INTRODUCCIÓN: PROMESA DE CAMPAÑA}

La posibilidad del empleador de reemplazar a sus trabajadores que se encuentren en huelga se estableció (impuso) en el año 1979, a través del Decreto Ley número $2758^{1}$, inserto dentro del llamado "Plan Laboral". El artículo 58 inciso segundo de dicha normativa, determinaba derechamente que "durante la huelga el empleador seguirá administrando la empresa y realizando cualquier función o actividad propia de ella, para cuyo efecto podrá contratar los trabajadores que considere necesarios". Las reformas laborales que la han precedido no han hecho más que regular esta situación. "Si bien la segunda reforma laboral prohibió formalmente el reemplazo de trabajadores en huelga, lo

\footnotetext{
* Abogado. Licenciado en Ciencias Jurídicas y Sociales de la Facultad de Derecho, Universidad de Chile. Candidato a Magister en Derecho del Trabajo y Seguridad Social, en la Universidad de Valencia y la Universidad de Talca.jrodriguez@alaboral.cl

${ }^{1}$ Del 06 de Julio del 1979, por el Ministerio del Trabajo y Previsión Social.
} 
que hace es sujetar a procedencia de dicho reemplazo a específicas exigencias, aunque algunas de ellas ya habían sido establecidas por la primera reforma laboral. Al efecto, la Ley $\mathrm{N}^{\circ} 19.759$ agregó, a las exigencias que deba tener la última oferta del empleador, la propuesta de 'un bono de reemplazo (...) por cada trabajador contratado como reemplazante.' La discusión que entonces se planteó se refirió al tipo de reemplazo de trabajadores: si la prohibición del reemplazo de trabajadores en huelga comprende sólo a los trabajadores externos, es decir se trataría de una "sustitución externa", de acuerdo a las categorías manejadas por la doctrina iuslaboralista, o si la prohibición abarca además a los trabajadores de la misma empresa, en cuanto se les encomendaría asumir las labores de los trabajadores huelguistas, es decir, una 'sustitución interna', en conformidad a las mismas categorías" (Rojas Miño, 2007: 217). En ambos sentidos osciló también la jurisprudencia, existiendo últimamente en la Excma. Corte Suprema una tendencia a prohibir también el reemplazo interno ${ }^{2}$.

Entendemos la Libertad Sindical como "el derecho que asiste a los trabajadores para constituir organizaciones, afiliarse o desafiliarse a ellas, a darse su propia normativa sin intervención de terceros $\mathrm{y}$, especialmente, el derecho al ejercicio de la actividad sindical por medio de aquellas acciones tendientes a la defensa y promoción de los intereses que le son propios, en particular, la negociación colectiva y el derecho a huelga" (Varas Castillo, 2003: 3). (Al permitirse el reemplazo durante la huelga, sin duda se despotencia este último derecho, limitándolo excesivamente. De esta forma, se vulnera derechamente la Libertad Sindical, consagrada en los Convenios números $87^{3}$ y $98^{4}$ de la OIT, ambos ratificados por Chile el 01 de Febrero de $1999^{5}$. Así lo ha confirmado el Comité de Libertad Sindical de la OIT, que ha concluido que "la Comisión toma nota de que el actual artículo 381 prohíbe de manera general el reemplazo de los huelguistas. Sin embargo, observa que sigue existiendo la posibilidad de proceder a dicho reemplazo mediante el cumplimiento de ciertas condiciones. El artículo actual contiene, además de las condiciones que ya existían, la del pago del bono de reemplazo a los huelguistas que vuelve más onerosa la contratación de nuevos trabajadores al empleador. No obstante, la Comisión recuerda que el reemplazo de los trabajadores menoscaba gravemente el derecho de huelga y repercute en el libre ejercicio de los derechos sindicales. La Comisión pide al Gobierno que modifique su legislación para garantizar que las empresas no puedan

\footnotetext{
${ }^{2}$ Tales como los fallos dictados por la Cuarta Sala, el 12 de Mayo 2015 (bajo el rol 15.293-14), 29 de Enero del 2015 (bajo el rol 10.444-2014), 04 de Diciembre de 2014 (bajo el rol 3.514-2014) y mas antiguamente el 11 de Septiembre de 2007 (bajo el rol 5.673-2006).

${ }^{3} \mathrm{Al}$ respecto, su Artículo $3 \mathrm{n}^{\circ} 1$ establece que "Las organizaciones de trabajadores y de empleadores tienen el derecho de redactar sus estatutos y reglamentos administrativos, el de elegir libremente sus representantes, el de organizar su administración y sus actividades y el de formular su programa de acción".

${ }^{4} \mathrm{Al}$ respecto, su Artículo 4 establece que "Deberán adoptarse medidas adecuadas a las condiciones nacionales, cuando ello sea necesario, para estimular y fomentar entre los empleadores y las organizaciones de empleadores, por una parte, y las organizaciones de trabajadores, por otra, el pleno desarrollo y uso de procedimientos de negociación voluntaria, con objeto de reglamentar, por medio de contratos colectivos, las condiciones de empleo".

${ }^{5}$ En:

http://www.ilo.org/dyn/normlex/es/f?p=NORMLEXPUB:11200:0::NO::P11200 COUNTRY ID:102588 (visitado el 05 de Septiembre del 2016).
} 
contratar nuevos trabajadores en sustitución de sus empleados mientras éstos realizan una huelga legal."6 Aquí nace entonces el problema jurídico-laboral que analizaremos.

El Gobierno actual quiso hacerse cargo de este problema histórico y reconoció en la página 93 de su Programa de Gobierno que "el año 2000, entró en vigencia el Convenio OIT N ${ }^{\circ} 87$ sobre Libertad Sindical y la Protección del Derecho de Sindicalización, ratificado por el Congreso Nacional. El país ha sido notificado en distintas oportunidades tanto por la OIT (2008 y 2012) como por Naciones Unidas (2004) en cuanto a que la norma laboral de los reemplazos durante la huelga constituyen un incumplimiento de este convenio y de la libertad sindical. Avanzaremos en el respeto a la libertad sindical conforme a las normas y convenios que Chile ha ratificado en materia laboral" 7 . A continuación, revisaremos si la Reforma Laboral que se presentó al efecto el 29 de Diciembre de 2014 bajo el número de boletín 9835-13 ${ }^{8}$ (en adelante "Reforma Laboral"), soluciona el problema jurídico-laboral de estar violando convenios internacionales que nos obligamos a cumplir como país.

\section{HISTORIA DE LA LEY DEL REEMPLAZO DE TRABAJADORES HUELGUISTAS EN LA REFORMA LABORAL}

Para comenzar, es necesario recordar el marco normativo que se arrastraba desde las reformas anteriores y el cual se pretendía modificar. El artículo fundamental que regula el reemplazo durante la huelga es el artículo 381 del Código del Trabajo, el cual establece lo siguiente:

"Estará prohibido el reemplazo de los trabajadores en huelga, salvo que la última oferta formulada, en la forma y con la anticipación indicada en el inciso tercero del artículo 372, contemple a lo menos:

a) Idénticas estipulaciones que las contenidas en el contrato, convenio o fallo arbitral vigente, reajustadas en el porcentaje de variación del Índice de Precios al Consumidor determinado por el Instituto Nacional de Estadísticas o el que haga sus veces, habido en el período comprendido entre la fecha del último reajuste y la fecha de término de vigencia del respectivo instrumento;

b) Una reajustabilidad mínima anual según la variación del Índice de Precios al Consumidor para el período del contrato, excluidos los doce últimos meses;

c) Un bono de reemplazo, que ascenderá a la cifra equivalente a cuatro unidades de fomento por cada trabajador contratado como reemplazante.

La suma total a que ascienda dicho bono se pagará por partes iguales a los trabajadores involucrados en la huelga, dentro de los 5 días siguientes a la fecha en que ésta haya finalizado.

\footnotetext{
${ }^{6} \mathrm{En}:$

http:/www.ilo.org/dyn/normlex/en/f?p=NORMLEXPUB:13100:0::NO::P13100_COMMENT ID,P13100 L ANG CODE:2201675,es (visitado el 05 de Septiembre del 2016).

${ }^{7}$ En: http://www.gob.cl/programa-de-gobierno/ (visitado el 05 de Septiembre del 2016).

8 En: https://www.camara.cl/pley/pdfpley.aspx?prmID=10046\&prmTIPO=INICIATIVA (visitado el 05 de Septiembre del 2016).
} 
En este caso, el empleador podrá contratar a los trabajadores que considere necesarios para el desempeño de las funciones de los involucrados en la huelga, a partir del primer día de haberse hecho ésta efectiva.

Además, en dicho caso, los trabajadores podrán optar por reintegrarse individualmente a sus labores, a partir del décimo quinto día de haberse hecho efectiva la huelga.

Si el empleador no hiciese una oferta de las características señaladas en el inciso primero, y en la oportunidad que allí se señala, podrá contratar los trabajadores que considere necesarios para el efecto ya indicado, a partir del décimo quinto día de hecha efectiva la huelga, siempre y cuando ofrezca el bono a que se refiere la letra c) del inciso primero de este artículo. En dicho caso, los trabajadores podrán optar por reintegrarse individualmente a sus labores, a partir del trigésimo día de haberse hecho efectiva la huelga.

Si la oferta a que se refiere el inciso primero de este artículo fuese hecha por el empleador después de la oportunidad que allí se señala, los trabajadores podrán optar por reintegrarse individualmente a sus labores, a partir del décimo quinto día de materializada tal oferta, o del trigésimo día de haberse hecho efectiva la huelga, cualquiera de estos sea el primero. Con todo, el empleador podrá contratar a los trabajadores que considere necesarios para el desempeño de las funciones de los trabajadores involucrados en la huelga, a partir del décimo quinto día de hecha ésta efectiva.

En el caso de no existir instrumento colectivo vigente, la oferta a que se refiere el inciso primero se entenderá materializada si el empleador ofreciere, a lo menos, una reajustabilidad mínima anual, según la variación del Índice de Precios al Consumidor para el período del contrato, excluidos los últimos doce meses.

Para los efectos de lo dispuesto en este artículo, el empleador podrá formular más de una oferta, con tal que al menos una de las proposiciones cumpla con los requisitos que en él se señalan, según sea el caso, y el bono a que se refiere la letra c) del inciso primero de este artículo.

Si los trabajadores optasen por reintegrarse individualmente a sus labores de conformidad a lo dispuesto en este artículo, lo harán, al menos, en las condiciones contenidas en la última oferta del empleador.

Una vez que el empleador haya hecho uso de los derechos señalados en este artículo, no podrá retirar las ofertas a que en él se hace referencia."

Este artículo fue totalmente eliminado, junto al resto del Libro IV, por el artículo 1 número 23 de la Reforma Laboral. En su lugar, consagraba el siguiente artículo 349: "Derecho a huelga. La huelga es un derecho que debe ser ejercido colectiva y pacificamente por los trabajadores.

Se prohíbe el reemplazo de los puestos de trabajo de los trabajadores en huelga. La infracción de esta prohibición constituye una práctica desleal grave, habilitando a la Inspección del Trabajo para requerir el retiro inmediato de los trabajadores reemplazantes de los puestos de trabajo en huelga." Luego, regulaba en el mismo artículo la situación de oposición del empleador, junto a las medidas de reparación del artículo 408 
y calificándolo nuevamente como una "práctica desleal" en el artículo 411. Más allá de la calificación de "pacíficamente" en cuanto al ejercicio de la huelga (que se eliminó posteriormente), se rescata la prohibición absoluta y sin matices del reemplazo durante la huelga. Sin embargo, esta regulación no tuvo el piso político necesario.

\subsection{INDICACIONES}

El 14 de Julio de 2015 el Gobierno introdujo una de las tantas indicaciones, donde propone el artículo 347 (reemplaza al 349 que citamos anteriormente) y que consagra el "Derecho a Huelga": "La huelga es un derecho que debe ser ejercido colectivamente (ya no más "pacíficamente") por los trabajadores. Se prohíbe el reemplazo de los trabajadores en huelga. La huelga no afectará la libertad de trabajo de los trabajadores no involucrados en ella, ni la ejecución de las funciones convenidas en sus contratos de trabajo. La infracción de la prohibición señalada en el inciso segundo constituye una práctica desleal grave, la que habilitará a la Inspección del Trabajo para requerir el retiro inmediato de los trabajadores reemplazantes." Por primera vez se introduce el concepto constitucional (artículo 19 número 16 de la Constitución) de "Libertad de Trabajo" de los no huelguistas. Asimismo, también se introduce por primera vez el concepto de "adecuaciones necesarias", a través de la indicación que agregaba lo siguiente al artículo 406 sobre prácticas desleales: "Los trabajadores no involucrados en la huelga podrán ejecutar las funciones convenidas en sus contratos. El empleador en el ejercicio de sus facultades legales podrá efectuar las adecuaciones necesarias con este objeto, incluidos ajustes a los turnos u horarios de trabajo, sin que lo previsto en este párrafo constituya práctica desleal." Luego, el 9 de Diciembre siguiente, precisó su primera frase, resultando de la siguiente manera: "Los trabajadores no involucrados en la huelga ejecutarán las funciones convenidas en sus contratos de trabajo" ". Le quitó la palabra "podrá" y aclaró que se trataban contratos "de trabajo", lo que no aparece de ninguna relevancia. Finalmente, en la última tanda de indicaciones, el 02 de Marzo de 2016 el Gobierno elimina toda esa frase e integra todo en el siguiente párrafo: "El empleador en el ejercicio de sus facultades legales, podrá modificar los turnos u horarios de trabajo, y efectuar las adecuaciones necesarias con el objeto de asegurar que los trabajadores no involucrados en la huelga puedan ejecutar las funciones convenidas en sus contratos de trabajo, sin que constituya práctica desleal ni importe una infracción a la prohibición de reemplazo."

\subsection{INTERPRETACIONES}

\subsection{1. "ADECUACIONES NECESARIAS"}

\footnotetext{
${ }^{9}$ Ambas indicaciones en Congreso Nacional de Chile. "Boletín $\mathrm{n}^{\circ}$ 9.835-13 segundo boletín de indicaciones 9-diciembre-2015. Indicaciones formuladas durante la discusión en general del proyecto de ley, en segundo trámite constitucional, que moderniza el sistema de relaciones laborales, introduciendo modificaciones al Código del Trabajo". p. 132 y 133, respectivamente.
} 
Este último cambio al que aludíamos al final del numeral anterior, aunque parezca sutil, creemos que ya comienza a entregarnos el sentido que quiso darle el legislador que propuso la norma. En un comienzo, la frase "podrá efectuar las adecuaciones necesarias con este objeto, incluidos ajustes a los turnos u horarios de trabajo" da cuenta de una relación de género a especie, donde las "adecuaciones necesarias" son el género y los "ajustes a los turnos u horarios de trabajo" son la especie, ya que estos últimos se entienden "incluidos" en este. Así lo concluimos tomando el elemento lógico como una herramienta de interpretación general, consagrado en el artículo 19 inciso segundo y artículo 22 del Código Civil, ya que es una relación lógica "claramente manifestados en ella misma" y que guarda "entre todas ellas la debida correspondencia y armonía". De esta forma, se delimita en primer término el sentido de "adecuaciones necesarias": se refiere a cambios tales como la jornada y siempre "con el objeto" de que "los trabajadores no involucrados en la huelga ejecutarán las funciones convenidas en sus contratos de trabajo". Luego, con la última indicación, separa los conceptos de "adecuaciones necesarias" y "turnos u horarios de trabajo", lo que podría aprovecharse como una oportunidad para interpretar mas laxamente las "adecuaciones necesarias", pero el legislador ya le había dado un alcance más limitado con ajustes tales como la modificación a los turnos y horarios de trabajo, siempre con el objeto de que los trabajadores no involucrados en la huelga cumplan con las funciones convenidas en sus contratos de trabajo. Ahora se abre una nueva fuente de interpretación: ¿A qué se refiere con las "funciones convenidas en sus contratos de trabajo"?

\subsection{2. "FUNCIONES CONVENIDAS EN SUS CONTRATOS DE TRABAJO”}

Rescatando el elemento histórico, de la "historia fidedigna de su establecimiento", en los términos del artículo 19 inciso segundo del Código Civil, la discusión que se llevó a cabo sobre las "funciones convenidas en sus contratos de trabajo" se batió entre si dichas funciones debían ser habituales o no, en aplicación del principio de la Primacía de la Realidad. Por ello, la senadora Adriana Muñoz, propuso introducir el siguiente inciso: "Las adecuaciones destinadas a posibilitar el cumplimiento de los contratos de los trabajadores no afectos a la huelga no podrá significar el ejercicio de funciones que, aún convenidas en sus contratos, no hayan sido realizadas habitualmente." 10 . Asimismo, los senadores Juan Pablo Letelier y Carolina Goic: "Los trabajadores no involucrados en la huelga sólo ejecutarán las funciones convenidas y habitualmente ejecutadas en sus contratos. Podrán consentir con el empleador sólo ajustes de horarios, según lo indicado en el artículo 12, durante la huelga." "11. Por otro lado, los senadores Allamand, Chahuán, Larraín y Pérez Varela propusieron reponer la primera redacción propuesta por el Gobierno ${ }^{12}$, donde prevalecía la característica de "funciones convenidas" y se excluye la habitualidad. Por último, los senadores De Urresti, Montes, Muñoz, y Letelier, propusieron incluir un nuevo

\footnotetext{
${ }^{10}$ Congreso Nacional de Chile. "Boletín No 9.835-13. Tercer boletín de indicaciones. Indicaciones formuladas durante la discusión en general del proyecto de ley, en segundo trámite constitucional, que moderniza el sistema de relaciones laborales, introduciendo modificaciones al Código del Trabajo". 2 de marzo del 2015, número 207, p. 98.

${ }^{11}$ Congreso Nacional de Chile. op. cit., número 364 a), p. 140.

${ }^{12}$ Congreso Nacional de Chile. op. cit., número 365 c), p. 141.
} 
numeral sobre práctica desleal: "Imponer la ejecución de funciones que no hayan realizado habitualmente a trabajadores no involucrados en la huelga con el objeto de reemplazar los puestos de trabajo de los huelguistas." 13

No cabe aquí reproducir todo el debate parlamentario que se dio al respecto, pero sí merece mencionarse la exposición de la Ministra del Trabajo y Previsión Social, Ximena Rincón. Comienza diciendo que "Algunos critican la reciente indicación en que se usa la frase "Adecuaciones necesarias", alegando que abre espacio para el remplazo interno, y otros lo hacen señalando que lo impedirá. Es necesario, entonces, fijar el sentido y alcance de la propuesta del Ejecutivo en una materia que ha adquirido alta importancia en el debate político, pero que se debe contextualizar en la discusión técnica propia de la tramitación legislativa de este proyecto, esencialmente para fijar el sentido y alcance de la propuesta". Se puede ver entonces, que la intención del legislador es justamente establecer en la Historia de la Ley su correcta interpretación. Señala que "De esta forma, el principio rector que orienta la interpretación es el aseguramiento de las funciones contenidas en el contrato de los trabajadores no huelguistas, sea que estén explícitas, o que, de no estarlo, correspondan a funciones que desarrollen en la práctica. La jurisprudencia judicial y administrativa sostiene que las funciones o cualquier otra cláusula del contrato de trabajo incluyen no solo lo establecido explícitamente en ese contrato, sino también lo que en la práctica se verifica. Ello se sustenta en el principio de la "primacía de la realidad" (así se llama, aunque a algunos les moleste que nosotros ocupemos ese término), en virtud del cual en el ámbito de las relaciones laborales prima lo que sucede en la realidad por sobre lo establecido en documentos, que pueden ser aparentes o falsos. De tal modo, si el empleador pone en el contrato de trabajo un listado de funciones que el trabajador no huelguista no realiza en la práctica, y que corresponden a funciones de trabajadores que en el futuro podrían estar en huelga (falsa polifuncionalidad), en consideración al principio en comento debería estarse a la realidad y no a las apariencias documentales" 14 .

Lo señalado por la ministra marcó la continuación del debate parlamentario, debatiéndose entre la necesidad del requisito de habitualidad en las funciones de los trabajadores no huelguistas o si simplemente bastaba con que fueran convenidas previamente. Esta exposición trajo ronchas, incluso dentro del mismo Gobierno, específicamente con el Ministro de Hacienda ${ }^{15}$, pero nació de una necesidad de una mayor aclaración de un término extremadamente laxo e interpretable como "adecuaciones necesarias" o "convenidas".

\subsection{3. "EL EMPLEADOR EN EL EJERCICIO DE SUS FACULTADES LEGALES, PODRÁ MODIFICAR LOS TURNOS U HORARIOS DE TRABAJO”}

\footnotetext{
${ }^{13}$ Congreso Nacional de Chile. op. cit., número 367-370, p. 141-142.

${ }^{14}$ Congreso Nacional de Chile. "Boletín $\mathrm{n}^{\circ}$ 9.835-13. discusión particular del proyecto de ley, en segundo trámite constitucional, que moderniza el sistema de relaciones laborales, introduciendo modificaciones al código del trabajo. 10 de marzo del 2015, números $106^{\mathrm{a}} / 363$, págs. $76-80$.

15 En: http://www.latercera.com/noticia/politica/2016/03/674-673048-9-problemas-bajo-la-mesa.shtml (visitado el 05 de Septiembre del 2016).
} 
Por último, cabe aclarar si la modificación de "turnos u horarios de trabajo" que contempla la norma, se trata de una nueva facultad unilateral del empleador o si debe someterse al resto de la legislación o al consentimiento del trabajador. Rescatando nuevamente la Historia de la Ley y el elemento histórico de interpretación, debemos rescatar los dichos del senador Letelier, quien fue el único que se refirió al respecto. Así, "manifestó que los ajustes o turnos y horarios requieren, en cualquier caso, la anuencia del trabajador con la finalidad que tales modificaciones puedan ser impuestas con el único fin de afectar el ejercicio del derecho a huelga". Asimismo, luego agregó que "la norma se inserta dentro de una serie de disposiciones que impiden la limitación del ejercicio del derecho a huelga y prohíben, en cualquier caso, el reemplazo interno de trabajadores. En consecuencia, aseveró que ningún cambio de turno u horario puede tener un fin distinto a permitir que los trabajadores no involucrados en la huelga puedan desempeñar sus funciones" "16. Finalmente, tal como señalamos anteriormente, el mismo senador junto a la senadora Carolina Goic propusieron la siguiente indicación: "Los trabajadores no involucrados en la huelga sólo ejecutarán las funciones convenidas y habitualmente ejecutadas en sus contratos. Podrán consentir con el empleador sólo ajustes de horarios, según lo indicado en el artículo 12, durante la huelga."17.

Utilizando los elementos lógicos y sistemáticos de interpretación, consagrados en el artículo 22 del Código Civil, debemos interpretar esta facultad en armonía con el artículo 12 del Código del Trabajo, donde se encuentra la facultad del empleador de modificar la jornada de trabajo. Recordemos que este artículo establece requisitos que parecen impracticables dentro de la huelga, como el hecho de que se debe "dar el aviso correspondiente al trabajador con treinta dias de anticipación a lo menos". Por ello, nos parece razonable lo dicho por la ministra Rincón, en cuanto a que "la figura contenida en el artículo 12 del Código del Trabajo -consistente en el ius variandi- no resulta aplicable a los ajustes a los turnos y horarios propios durante el ejercicio del derecho a huelga"18. En definitiva, con esta interpretación nace una nueva facultad legal del empleador, donde "podrá modificar los turnos u horarios de trabajo" durante la huelga, solamente con el objeto de asegurar que los trabajadores no involucrados en la huelga puedan ejecutar las funciones convenidas en sus contratos de trabajo". Sin embargo, entendemos que no debe causar menoscabo al trabajador (tal como lo exige el artículo 12 y en general los principios del Derecho del Trabajo), para lo que traemos a colación el ejemplo que entregó la ministra en la prensa: "Si de 10 trabajadores que realizan el aseo industrial de una planta en la media hora de colación del resto de los trabajadores, la mitad de ellos está en huelga, claramente los otros cinco no van a poder hacer, en la media hora que tenían, el aseo que hacían diez trabajadores. Por lo tanto, el empleador podrá, por ejemplo, decirle al resto de los trabajadores: 'saben qué, chiquillos, no van a hacer su colación en media hora, la van a hacer en una hora a efecto de que la mitad de los trabajadores cumpla, no en el tiempo normal sino que en el doble de tiempo, la limpieza completa del establecimiento'. Esa es una adecuación necesaria. No estoy afectando derechos, no estoy suprimiendo

\footnotetext{
${ }^{16}$ Ambas citas en Congreso Nacional de Chile. "Informe complementario del segundo informe de la comisión de trabajo y previsión social, recaído en el proyecto de ley, en segundo trámite constitucional, que moderniza el sistema de relaciones laborales, introduciendo modificaciones al código del trabajo. Boletín N 9.835-13". p. 40.

${ }^{17}$ Congreso Nacional de Chile. Op. cit., número 364 a), p. 140.

${ }^{18}$ Congreso Nacional de Chile. Op. cit. p. 39.
} 
derechos. Simplemente estoy haciendo adecuaciones para que puedan trabajar los trabajadores". ${ }^{19}$

\section{CONCLUSIÓN Y SOLUCIÓN: LA JURISPRUDENCIA}

Ocupando finalmente el elemento sistemático del Artículo 22 inciso segundo del Código Civil, debemos analizar si esta Reforma Laboral cumple con lo exigido en los Convenios números 87 y 98 de la OIT, aplicables por el artículo 5 inciso segundo de nuestra Constitución Política. Tal como señaló el senador Letelier "el texto de la norma representa un aporte para el debate, pero la que va a resolver en el fondo es la jurisprudencia" ${ }^{20}$. Si se mantiene una interpretación acotada, sin duda se cumpliría con la Libertad Sindical consagrada en los convenios de la OIT, pero si se le da una interpretación extensiva, pasando por alto requisitos como la habitualidad de las funciones de los no huelguistas, se seguiría vulnerando la Libertad Sindical mediante el reemplazo interno. Hubiera sido deseable que la misma ley fijara el requisito de habitualidad, pero la negociación política solamente permitió que dicha interpretación quedara limitada a la Historia de la Ley. Esta redacción abrirá una excesiva judicialización en el futuro, que sin duda entorpecerá el ejercicio efectivo de la Huelga, con una ventana de entrada para el reemplazo interno que se pretendía eliminar. Pendiente queda la aplicación y análisis del nuevo artículo 306 inciso final, que señala que "La negociación colectiva en una empresa contratista o subcontratista no afectará las facultades de administración de la empresa principal, la que podrá ejecutar directamente o a través de un tercero la provisión de la obra o el servicio subcontratado que haya dejado de prestarse en caso de huelga." De esta forma, se permite derechamente el reemplazo, aunque sea de forma indirecta. Así se torna ineficaz cualquier huelga que intenten los trabajadores contratistas o subcontratistas, aunque el empleador contratista o subcontratista intentará solucionar la negociación colectiva en cuanto antes, con el fin de retomar el contrato comercial que lo une con la empresa principal.

Esta normativa no fue modificada por el veto presidencial $^{21}$ que significó la sentencia del Tribunal Constitucional del 09 de Mayo pasado ni tampoco fue afectada por el control preventivo de constitucionalidad que también realizó el 11 de Agosto pasado, por lo que la normativa que hemos analizado se consagró en el nuevo artículo 403 letra d) del Código del Trabajo, en el conjunto de la Reforma Laboral que fue promulgado el pasado 29 de Agosto de 2016. Solamente resta lo que decidan en la práctica nuestros tribunales, por lo que esperamos que resuelvan en Justicia, a la luz de la Libertad Sindical y de los convenios internacionales que nos obligamos a cumplir como país.

\section{BIBLIOGRAFÍA}

\footnotetext{
19 En: http://www.economiaynegocios.cl/noticias/noticias.asp?id=234294 (visitado el 05 de Septiembre del 2016).

${ }^{20}$ Congreso Nacional de Chile. Op. cit. 10 de Marzo del 2015, números $106^{\mathrm{a}} / 363$, p. 34.

21 En: https:/www.camara.cl/pdf.aspx?prmID=11788\%20\&prmTIPO=TEXTOSESION (visitado el 05 de Septiembre del 2016).
} 
ROJAS MIÑO, Irene (2007). Las reformas laborales al modelo normativo de negociación colectiva del Plan Laboral. Revista Ius et Praxis, año 13, $N^{\circ} 2$. Editorial Universidad de Talca.

VARAS CASTILLO, Mario (2003). Libertad sindical y negociación colectiva en Chile: un diagnóstico de la Ley $\mathrm{N}^{\circ} 19.759$. Boletín Oficial de la Dirección del Trabajo.

\section{DOCUMENTOS HISTORIA DE LA LEY}

1. Congreso Nacional de Chile. "Boletín No 9.835-13 Segundo boletín de indicaciones 9diciembre-2015. Indicaciones formuladas durante la discusión en general del proyecto de ley, en segundo trámite constitucional, que moderniza el sistema de relaciones laborales, introduciendo modificaciones al Código del Trabajo.”.

2. Congreso Nacional de Chile. "Boletín $\mathrm{N}^{0}$ 9.835-13. Tercer boletín de indicaciones. Indicaciones formuladas durante la discusión en general del proyecto de ley, en segundo trámite constitucional, que moderniza el sistema de relaciones laborales, introduciendo modificaciones al Código del Trabajo”. 2 de marzo del 2015, número 207.

3. Congreso Nacional de Chile. "Boletín $N^{0}$ 9.835-13. Discusión particular del proyecto de ley, en segundo trámite constitucional, que moderniza el sistema de relaciones laborales, introduciendo modificaciones al Código del Trabajo. 10 de marzo del 2015, números $106^{\mathrm{a}}$ / 363.

4. Congreso Nacional de Chile. "Informe complementario del segundo informe de la comisión de trabajo y previsión social, recaído en el proyecto de ley, en segundo trámite constitucional, que moderniza el sistema de relaciones laborales, introduciendo modificaciones al Código del Trabajo. Boletín N 9.835-13”. 